\title{
A Factor X-Activating Cysteine Protease from Malignant Tissue
}

\author{
StUART G. Gordon and Barbara A. Cross, Department of Medicine, University of \\ Colorado Health Sciences Center, Denver, Colorado 80262
}

A B S T RACT A proteolytic procoagulant has been identified in extracts of human and animal tumors and in cultured malignant cells. It directly activated Factor $\mathrm{X}$ but its similarity to other Factor $\mathrm{X}$-activating serine proteases was not clear. This study describes work done to determine whether this enzyme, cancer procoagulant, is a serine or cysteine protease. Purified cancer procoagulant from rabbit V2 carcinoma was bound to a $p$-chloromercurialbenzoate-agarose affinity column and was eluted with dithiothreitol. The initiation of recalcified, citrated plasma coagulation activity by cancer procoagulant was inhibited by $5 \mathrm{mM}$ diisopropylfluorophosphate, $1 \mathrm{mM}$ phenylmethylsulfonylfluoride, $0.1 \mathrm{mM} \mathrm{HgCl}$, and $1 \mathrm{mM}$ iodoacetamide. Activity was restored in the diisopropylfluorophosphate-, phenylmethylsulfonylfluoride-, and $\mathrm{HgCl}_{2}$-inhibited samples by $5 \mathrm{mM}$ dithiothreitol; iodoacetamide inhibition was irreversible. Russell's viper venom, a control Factor Xactivating serine protease, was not inhibited by either $0.1 \mathrm{mM} \mathrm{HgCl}_{2}$ or $1 \mathrm{mM}$ iodoacetamide. The direct activation of Factor $\mathrm{X}$ by cancer procoagulant in a two-stage assay was inhibited by diisopropylfluorophosphate and iodoacetamide. Diisopropylfluorophosphate inhibits serine proteases, and an undefined impurity in most commercial preparations inhibits cysteine proteases. Hydrolysis of diisopropylfluorophosphate with $\mathrm{CuSO}_{4}$ and imidazole virtually eliminated inhibition of thrombin, but cancer procoagulant inhibition remained complete, suggesting that cancer procoagulant was inhibited by the undefined impurity. These results suggest that cancer procoagulant is a cysteine endopeptidase, which distinguishes it from other coagulation factors including tissue factor. This and other data suggest that neoplastic cells produce this unique cysteine protease which may initiate blood coagulation.

\section{INTRODUCTION}

Factor $\mathrm{X}$ is the point of confluence of the intrinsic and extrinsic pathways in the coagulation cascade. Factor $\mathrm{X}$

Received for publication 6 October 1980 and in revised form 8 January 1981. is converted to its activated form (Factor $\mathrm{Xa}$ ) by the proteolytic removal of an activation glycopeptide with a molecular weight of $\sim 11,000(1,2)$. This activation can be facilitated by either Factors IXa and VIII, Factor VIIa and tissue factor, the autolytic conversion by Factor $\mathrm{Xa}$, or by an enzyme in the venom of Vipera Russelli (Russell's viper venom) (1-4). The active component within all of these Factor X-activating systems is a serine protease (1-5). In addition, Factor $\mathrm{X}$ can be activated by other serine proteases such as trypsin $(1,2,6)$, cathepsin $C(7)$, and the plant cysteine protease, papain (8).

Increased vascular thrombosis and the deposition of fibrin associated with malignant disease led us to look for an abnormal coagulation factor associated with neoplastic tissue. A proteolytic enzyme, cancer procoagulant, has been purified from rabbit V2 carcinoma and some of its physical, chemical, and enzymatic properties have been determined. ${ }^{1}$ In addition, cancer procoagulant activity has been identified in extracts of several human malignant tumors (9) and in cultured malignant cells ${ }^{2}(10-13)$ : This enzyme is inhibited by diisopropylfluorophosphate (DFP) ${ }^{3}$ and initiates coagulation in the absence of Factor VII by directly activating Factor X (14). Thus, we assumed that cancer procoagulant was a serine protease, similar to the other enzymes that activate Factor $\mathrm{X}$. These studies provide data which indicate that cancer procoagulant is not a serine protease but is a cysteine protease.

\section{METHODS}

Materials. A 0.5-M stock solution of DFP (Aldrich, Chemical Co., Milwaukee, Wis.) was prepared in dry iso-

\footnotetext{
${ }^{1}$ Gordon, Stuart G. Manuscript submitted for publication.

${ }^{2}$ Gordon, Stuart G., and B. Lewis. Manuscript submitted for publication.

${ }^{3}$ Abbreviations used in this paper: DFP, diisopropylfluorophosphate; DTT, dithiothreitol; MES, $2[N$-morpholine]ethane sulfonic acid; PCMB, p-chloromercurialbenzoateagarose; PMSF, phenylmethylsulfonylfluoride.
} 
propanol and diluted $1: 100$ in the sample to facilitate inhibition. A stock solution of $0.01 \mathrm{M} \mathrm{HgCl}_{2}$ was prepared in water and added to samples in a 1:100 ratio to a final concentration of $0.1 \mathrm{mM}$. A stock solution of $0.1 \mathrm{M}$ phenylmethylsulfonylfluoride (PMSF) (Sigma Chemical Co., St. Louis, Mo.) was prepared in dry dioxane and added to samples in a 1:100 ratio to a final concentration of $1 \mathrm{mM}$. A $1 \times 20-\mathrm{cm}$ $p$-chloromercurialbenzoate-agarose (PCMB) (Bio-Rad Laboratories, Richmond, Calif.) affinity column was prepared in $20 \mathrm{mM} 2[\mathrm{~N}$-morpholino]ethane sulfonic acid (MES) buffer (pH 6.8) to test the efficiency of cancer procoagulant binding and for the fractionation of the protease.

Citrated bovine and human plasma were obtained fresh and prepared as described previously (14) for use in the singlestage recalcified coagulation time assay. Pure bovine Factor $X$ was kindly provided by Dr. Earl Davie and used in the twostage clotting assay as described previously (14). Russell's viper venom (Sigma Chemical Co.) was used as a control Factor X-activating serine protease. Partially purified bovine thrombin (Parke Davis and Co., Detroit, Mich.) was diluted to $0.1 \mathrm{U} / \mathrm{ml}$ in $10 \mathrm{mM}$ veronal-buffered saline (pH 7.6).

Methods. General: Cancer procoagulant was purified from rabbit V2 carcinoma tumor tissue. ${ }^{4}$ Briefly, tumor tissue was removed surgically before the animal's death, extracted in three changes of $20 \mathrm{mM}$ veronal buffer ( $\mathrm{pH} \mathrm{7.8)}$ for $3 \mathrm{~h}$ each, and the pooled extracts were concentrated about 10 -fold over a PM-10 ultrafiltration membrane. The concentrated extract was applied to a benzamidine affinity chromatography column, unbound protein was washed from the column with $10 \mathrm{mM}$ veronal buffer $(\mathrm{pH}$ 7.9) containing $1 \mathrm{mM}$ EDTA and $50 \mathrm{mM} \mathrm{NaCl}$, and the bound protein was eluted with $1.0 \mathrm{M}$ propionic acid. After neutralizing the propionic acid with $\mathrm{NaOH}$, the sample was concentrated on a PM-10 ultrafiltration membrane, dialyzed, and applied to a 1.5-agarose gel filtration column. The high molecular weight, included protein peak containing the procoagulant activity was reapplied to a benzamidine affinity resin, the unbound protein was washed from the column with $10 \mathrm{mM}$ veronal buffer, adsorbed protein was eluted with $0.1 \%$ Triton $\mathrm{X}-100$, and then the bound protein was eluted with $0.5 \mathrm{M}$ propionic acid. After neutralizing and removing the propionic acid by dialysis, the concentrated sample was applied to a phenyl-Sepharose hydrophobic affinity column and the purified procoagulant was eluted with $10 \%$ dimethyl sulfoxide. The purified procoagulant sample was homogeneous by sodium dodecyl sulfate-polyacrylamide gel electrophoresis. At each step of the purification the procoagulant activity was assayed by measuring the recalcified coagulation time of citrated plasma (14) and its protein concentration with a modified Lowry method (15). Its sensitivity to DFP and its activity in Factor VIIdepleted bovine plasma $(14,16)$ were determined.

Affinity chromatography on PCMB resin. PCMB affinity resin was equilibrated in $25 \mathrm{mM}$ MES buffer (pH 6.8), packed in a $1 \times 10-\mathrm{cm}$ column and run at a flow rate of $\sim 1 \mathrm{ml} / \mathrm{min}$. About $1.0 \mathrm{ml}$ of a sample eluted from the second benzamidine affinity column was applied to the PCMB affinity resin in 20 $\mathrm{mM}$ veronal buffer (pH 7.7) and washed onto the column with $40 \mathrm{ml}$ of MES buffer ( $\mathrm{pH} 6.8$ ), $40 \mathrm{ml}$ of $1 \mathrm{M}$ urea and $1 \%$ Tween 20 in MES buffer, $20 \mathrm{ml}$ MES buffer to clear the urea and Tween from the column, $35 \mathrm{ml}$ of $0.1 \mathrm{mM}$ dithiothreitol (DTT), $35 \mathrm{ml}$ of $5 \mathrm{mM}$ DTT, $35 \mathrm{ml}$ of $10 \mathrm{mM}$ DTT, and finally $35 \mathrm{ml}$ of $100 \mathrm{mM}$ DTT to strip the column of residual protein. Protein eluted from the column was continuously monitored at $280 \mathrm{~nm}$ with an ISCO model UA-5 absorption monitor (Instrumentation Specialties Co., Lincoln, Neb.).

${ }^{4}$ Gordon, Stuart G. Manuscript submitted for publication.
The protein peaks were collected separately and concentrated $\sim 10$-fold on a PM-10 ultrafiltration membrane and dialyzed against MES buffer to remove the DTT. These samples were assayed for protein and procoagulant activity as described above.

Inhibition studies. Samples purified by the method described above and those obtained from the PCMB affinity column were tested for their inhibition by $5 \mathrm{mM}$ DFP, $1 \mathrm{mM}$ PMSF, $1 \mathrm{mM}$ iodoacetamide, and $0.1 \mathrm{mM} \mathrm{HgCl}_{2}$. In each case, samples of cancer procoagulant were assayed for procoagulant activity by measuring the single-stage recalcification clotting time of citrated human plasma with a fibrometer. The percent decrease in the clotting time of samples containing cancer procoagulant or controls compared to the appropriate $25 \mathrm{mM}$ MES buffer blank was used to quantify coagulant activity. Russell's viper venom was used as a coagulation control and as a Factor X-activating serine protease control. Portions of the samples and controls were treated with the appropriate inhibitors, incubated for $30 \mathrm{~min}$ at $37^{\circ} \mathrm{C}$, and reassayed for procoagulant activity. Portions of each sample were made 5 $\mathrm{mM}$ with DTT, incubated overnight at $5^{\circ} \mathrm{C}$, dialyzed for $3 \mathrm{~h}$ against two changes of $25 \mathrm{mM}$ MES buffer, and reassayed for procoagulant activity to determine if the inhibition had been effectively reversed by the reducing agent. In all studies, the activity of the untreated samples was compared with the same sample after inhibition and reactivation by a paired $t$-test analysis.

To determine whether cancer procoagulant was inhibited by DFP or by the conjectured impurity of DFP, samples of DFP were treated with cupric ion and imidazole to catalyze the hydrolysis of DFP (17) and tested for their inhibitory capacity at various times during the hydrolysis reaction (18). A solution of $25 \mathrm{mM} \mathrm{CuSO}_{4}$ and $25 \mathrm{mM}$ imidazole was prepared in water, adjusted to $\mathrm{pH} 7.6$ with $1 \mathrm{~N} \mathrm{NaOH}$, and made $10 \mathrm{mM}$ DFP by the addition of $0.5 \mathrm{M}$ DFP in isopropanol. The reaction mixture was incubated at $37^{\circ} \mathrm{C}$ for $2 \mathrm{~h}$ with constant stirring. Samples $(0.2 \mathrm{ml})$ of the reaction mixture were taken at 0,60 , and $120 \mathrm{~min}, \mathrm{pH}$ was adjusted to 7.6 , and $20 \mu \mathrm{l}$ of $250 \mathrm{mM}$ EDTA was added to stop the hydrolysis of DFP. A sample $(0.1 \mathrm{ml})$ of thrombin or cancer procoagulant was mixed with an equal volume of the EDTA-treated reaction mixture, incubated for $30 \mathrm{~min}$ at $37^{\circ} \mathrm{C}$, and assayed by measuring the recalcified clotting time as described above. Control thrombin, cancer procoagulant and buffer blank samples were mixed with the same amounts of $\mathrm{CuSO}_{4}$, imidazole, and EDTA, but containing isopropanol without DFP to determine the effect of these ingredients on the clotting assay.

The direct activation of Factor $X$. A two-stage coagulation assay was used, as described previously (14), to confirm that the protein eluted from the PCMB column and sensitive to the inhibitors could directly activate Factor X. In brief, purified bovine Factor $\mathrm{X}$ was incubated with either cancer procoagulant or Russell's viper venom in the first stage of the clotting assay. Samples were removed from the first stage and added to Factor VII- and Factor X-deficient bovine plasma (Sigma Chemical Co.) and the recalcified clotting time of the second stage was measured with a fibrometer. Both inhibited and uninhibited samples were assayed for their ability directly to activate Factor $X$. The results are expressed as the normalized clotting time of the second stage of the assay.

\section{RESULTS}

PCMB-affinity chromatography. A partially purified V2 carcinoma extract sample containing cancer procoagulant was applied to the PCMB affinity column (Fig. 1). Protein was eluted in each of the six washes. 


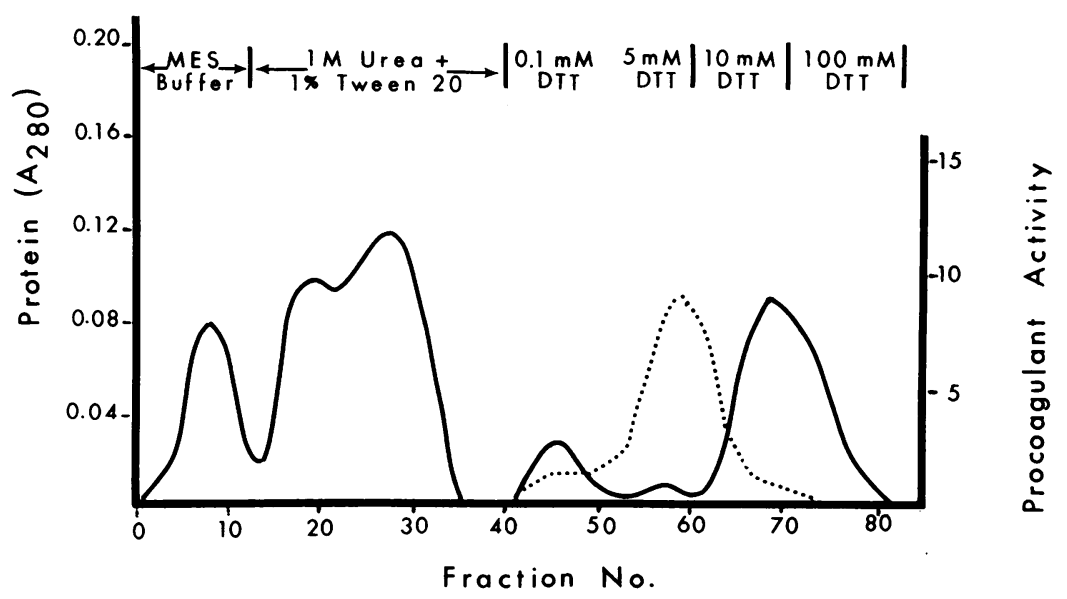

FIGURE 1 An elution profile of the PCMB chromatography column. A partially purified rabbit V2 carcinoma extract was applied to the affinity column. The column was eluted with $40 \mathrm{ml}$ of $25 \mathrm{mM}$ MES Buffer (pH 6.8), $40 \mathrm{ml}$ of $1 \mathrm{M}$ urea and 1\% Tween 20 in $25 \mathrm{mM}$ MES buffer; urea and Tween 20 were washed off the column with $20 \mathrm{ml}$ of MES buffer; and the bound protein was eluted with $35 \mathrm{ml}$ of $0.1 \mathrm{mM}$ DTT, $35 \mathrm{ml}$ of $5 \mathrm{mM}$ DTT, $35 \mathrm{ml}$ of $10 \mathrm{mM}$ DTT, and $35 \mathrm{ml}$ of $100 \mathrm{mM}$ DTT. Eluted protein (-) was monitored by reading absorption at $280 \mathrm{~nm}$ and procoagulant activity $(\cdots)$ was assayed by measuring the recalcification clotting time of normal citrated human plasma.

A small amount of procoagulant activity was eluted in $0.1 \mathrm{mM}$ DTT with the major peak of activity in the 5 mM eluate.

Inhibition studies. Studies of the inhibition characteristics of purified cancer procoagulant were performed in an effort to determine whether it was a serine or cysteine protease. Purified cancer procoagulant was treated with $5 \mathrm{mM}$ DFP, $1 \mathrm{mM}$ PMSF, $0.1 \mathrm{mM} \mathrm{HgCl}_{2}$, and $1 \mathrm{mM}$ iodoacetamide. The inhibited samples were assayed for procoagulant activity (Table I). Treatment of the inhibited enzyme with $5 \mathrm{mM}$ DTT effectively reactivated samples inhibited with DFP, PMSF, and $\mathrm{HgCl}_{2}$. Iodoacetamide inhibition was irreversible. Russell's viper venom, the control Factor $\mathrm{X}$-activating serine protease, was treated with $0.1 \mathrm{mM} \mathrm{HgCl}_{2}$ and $1 \mathrm{mM}$ iodoacetamide. It was not inhibited by either $\mathrm{HgCl}_{2}$ or iodoacetamide.

To determine whether iodoacetamide treatment might denature cancer procoagulant rather than block its active site, a PMSF-treated sample was made $1 \mathrm{mM}$ with iodoacetamide and then treated with $5 \mathrm{mM}$ DTT, dialyzed, and analyzed for activity. There was no procoagulant activity after treatment with PMSF or after iodoacetamide treatment, but full activity was recovered after reductive DTT reactivation. A similar double inhibition was performed to determine whether DFP and iodoacetamide reacted at the same site on the enzyme. A DFP-inhibited sample was made $1 \mathrm{mM}$ with iodoacetamide and then reactivated with $5 \mathrm{mM}$ DTT. There was no clotting activity after DFP and iodoacetamide treatment but reactivation with DTT facilitated recovery of full activity, whereas the inhibition of the control cancer procoagulant sample, treated with iodoacetamide alone, was irreversible.

Cupric ion and imidazole catalyze the hydrolysis of DFP with the release of hydrofluoric acid (17); in these experiments the decrease in $\mathrm{pH}$ confirmed that the reaction was proceeding. In four experiments, the clotting time of the untreated thrombin control and the purified cancer procoagulant sample was $112 \pm 4$ and $130 \pm 8 \mathrm{~s}$, respectively, after normalizing the results to a 200-s blank time. Thrombin and cancer procoagulant were treated with the DFP hydrolysis mixture immediately after it was prepared $(0 \mathrm{~min})$ and after 60 and $120 \mathrm{~min}$ incubations at $37^{\circ} \mathrm{C}$. Thrombin activity decreased to $9 \pm 6 \%$ of its original clotting activity after reacting with the 0-min DFP hydrolyzate (Fig. 2). After treatment with the 60- and 120-min DFP hydrolyzate, thrombin activity was about 50 and $92 \%$ of its original level, respectively. In contrast, cancer procoagulant activity was almost completely inhibited after treatment with 0-, 60-, and 120-min DFP hydrolyzate. These results suggest that the inhibitor of thrombin was hydrolyzed by the $\mathrm{CuSO}_{4}$-imidazole reaction, whereas the cancer procoagulant inhibitor was not destroyed under these conditions.

To confirm that the procoagulant activity blocked by the inhibitors was activating Factor $\mathrm{X}$ as previously described (10), a two-stage clotting assay was performed. Both DFP and iodoacetamide effectively inhibited the activation of Factor $X$ by cancer procoagulant in the first stage of the assay (Fig. 3). Iodoacetamide did not affect the activity of the Russell's viper venom control as expected. 
TABLE I

The Effect of Various Inhibitors on the Coagulation Activity of Russell's Viper Venom and Purified Cancer Procoagulant

\begin{tabular}{|c|c|c|c|c|c|c|}
\hline & \multirow[b]{2}{*}{$n$} & \multicolumn{2}{|c|}{ Clotting time } & \multirow{2}{*}{$\begin{array}{c}\text { Mean } \\
\text { difference }\end{array}$} & \multirow[b]{2}{*}{$P$} & \multirow[b]{2}{*}{ Inhibited } \\
\hline & & Untreated & Treated & & & \\
\hline & & \multicolumn{2}{|c|}{$s$} & & & $\%$ \\
\hline \multicolumn{7}{|c|}{$\begin{array}{l}\text { Cancer procoagulant } \\
\text { DFP }\end{array}$} \\
\hline inhibited & 7 & $175 \pm 3$ & $201 \pm 4$ & $26 \pm 1$ & $<0.005$ & 100 \\
\hline reactivated & 3 & $181 \pm 2$ & $168 \pm 6$ & $-13 \pm 6$ & NS & 0 \\
\hline \multicolumn{7}{|l|}{ PMSF } \\
\hline inhibited & 6 & $175 \pm 4$ & $207 \pm 10$ & $32 \pm 11$ & $<0.025$ & 100 \\
\hline reactivated & 5 & $171 \pm 3$ & $167 \pm 7$ & $-4 \pm 8$ & NS & 0 \\
\hline \multicolumn{7}{|l|}{$\mathrm{HgCl}_{2}$} \\
\hline inhibited & 6 & $168 \pm 5$ & $204 \pm 5$ & $36 \pm 2$ & $<0.005$ & 100 \\
\hline reactivated & 5 & $172 \pm 4$ & $176 \pm 7$ & $4 \pm 4$ & NS & 14 \\
\hline \multicolumn{7}{|l|}{ IA } \\
\hline inhibited & 8 & $172 \pm 4$ & $200 \pm 2$ & $28 \pm 5$ & $<0.005$ & 100 \\
\hline reactivated & 3 & $166 \pm 9$ & $202 \pm 8$ & $36 \pm 4$ & $<0.005$ & 100 \\
\hline \multicolumn{7}{|c|}{ Russell's viper venom } \\
\hline \multicolumn{7}{|l|}{$\mathrm{HgCl}_{2}$} \\
\hline inhibited & 3 & $159 \pm 11$ & $160 \pm 5$ & $1 \pm 14$ & NS & 0 \\
\hline \multicolumn{7}{|l|}{ IA : } \\
\hline inhibited & 5 & $157 \pm 6$ & $146 \pm 15$ & $-11 \pm 18$ & NS & 0 \\
\hline
\end{tabular}

Samples were made $5 \mathrm{mM}$ DFP, $1 \mathrm{mM}$ PMSF, $0.1 \mathrm{mM}$ mercuric chloride $\left(\mathrm{HgCl}_{2}\right)$, or $1 \mathrm{mM}$ iodoacetamide (IA) and incubated for $30 \mathrm{~min}$ at $37^{\circ} \mathrm{C}$. To reactivate the inhibited coagulant activity, portions of the samples were made $5 \mathrm{mM}$ DTT, incubated at $5^{\circ} \mathrm{C}$ overnight, and dialyzed for $3 \mathrm{~h}$ against $25 \mathrm{mM}$ MES buffer (pH 6.8). The untreated samples, inhibitor-treated samples, and reactivated samples were assayed for activity by measuring the recalcified clotting time of normal citrated human plasma. The results are expressed as the mean clotting time of $(n)$ untreated and treated samples \pm SEM normalized to a blank clotting time of $200 \mathrm{~s}$. The mean difference $\pm S E$ of the difference between the activities of the untreated sample and its inhibited or reactivated counterpart was compared to a paired $t$ test. The relative change in activity after inhibition and reactivation is expressed as a percent inhibition.

\section{DISCUSSION}

Recently, cancer procoagulant was purified and some of its physicochemical characteristics were determined (14). It is a proteolytic enzyme that is inhibited by DFP, facilitates clotting of Factor VIIdepleted plasma, and initiates coagulation by directly activating Factor $X$ in the coagulation cascade. Until recently, it was assumed that cancer procoagulant was a serine protease because it was inhibited by $5 \mathrm{mM} \mathrm{DFP}$, there was effective binding of cancer procoagulant to a benzamidine-Sepharose affinity column, and it mimicked the behavior of other coagulation serine proteases (Factors IXa and VIIa and the Factor X-activating protease in Russell's viper venom) that are known to activate Factor $X$ (1-5). However, during studies to determine the optimum conditions for the release of tritium-labeled activation peptide from ${ }^{3} \mathrm{H}$-Factor $\mathrm{X}$ (19) by cancer procoagulant, the optimum $\mathrm{pH}$ for the activation of Factor $\mathrm{X}$ was found to be $\sim 6.5 .^{5}$ Since serine proteases are more active between $\mathrm{pH} 7$ and 9 (20), and cysteine proteases (thiol and sulfhydryl proteases) are more active between $\mathrm{pH} 5$ and $7(20,21)$, this observation suggested that cancer procoagulant might be a cysteine protease. This led us to study the effect of specific inhibitors on cancer procoagulant activity in an effort to determine whether cancer procoagulant was a serine or cysteine protease.

Cysteine proteases are inhibited by PCMB and will bind to a PCMB ligand linked to agarose $(22,23)$. The reasonably specific nature of the binding of cysteine proteases to a PCMB-agarose affinity column provides evidence suggesting that cancer procoagulant may be a cysteine protease. Free sulfydryl groups on other proteins will bind to a PCMB affinity resin $(24,25)$, but the specificity and avidity of this binding may be less

\footnotetext{
${ }^{5}$ Manuscript in preparation.
} 


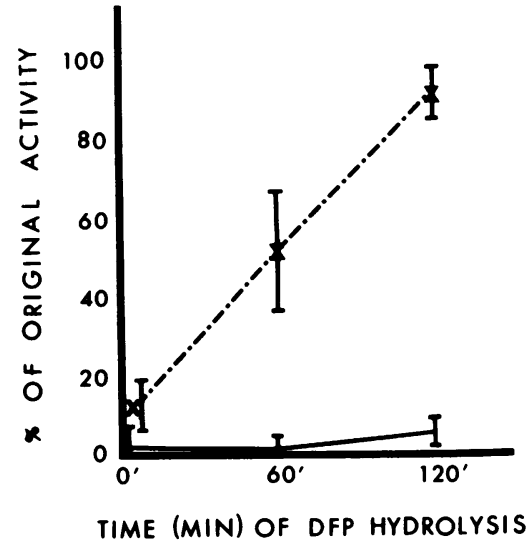

FIGURE 2 Effect of DFP hydrolysis on the inhibition of thrombin and cancer procoagulant. Equimolar amounts of $\mathrm{CuSO}_{4}$ and imidazole $(25 \mathrm{mM})$ were incubated with $10 \mathrm{mM}$ DFP at $37^{\circ} \mathrm{C}$ for $2 \mathrm{~h}$ to catalyze the hydrolysis of DFP to diisopropylphosphate and HF. Samples $(0.2 \mathrm{ml})$ of the hydrolyzate were removed immediately after preparing the reaction mixture $(0 \mathrm{~min})$ and after 60 and $120 \mathrm{~min}$, and the reaction was stopped with $20 \mu \mathrm{l}$ of $250 \mathrm{mM}$ EDTA. Thrombin $(\cdots)$ ) or cancer procoagulant $(\longrightarrow)$ samples $(0.1 \mathrm{ml})$ were mixed with $0.1 \mathrm{ml}$ of the hydrolyzate, incubated for $30 \mathrm{~min}$ at $37^{\circ} \mathrm{C}$, and assayed by measuring the clotting time of recalcified citrated plasma. The results are expressed as the mean percent of activity in the initial, untreated thrombin or cancer procoagulant sample $\pm \operatorname{SEM}(n=4)$.

than when the active site of an enzyme recognizes the PCMB ligand. The results demonstrate that cancer procoagulant binds to the PCMB affinity resin and is not eluted by $1 \mathrm{M}$ urea and $1 \%$ Tween 20 with the other adsorbed proteins and is effectly removed with DTT, properties that are consistent with the concept that cancer procoagulant may be a cysteine protease.

One of the effective ways to distinguish between serine and cysteine proteases is to inactivate them selectively by means of specific inhibitors $(20,21)$. DFP and PMSF are well-known irreversible inhibitors of serine proteases $(20,26,27)$; PMSF is a less effective inhibitor of cysteine proteases, and is reversible $(20,21$, 28 ); and the DFP inhibition of cysteine proteases is controversial, as discussed below. Iodoacetamide and mercury are more specific inhibitors for cysteine proteases and are less effective or even ineffective for the inhibition of serine proteases (20-22). Cancer procoagulant was inhibited by all four inhibitors, and the inhibition by DFP, PMSF, and mercury was reversed by reductive removal of the inhibitors. Inhibition by iodoacetamide was irreversible. To determine whether the inhibition by iodoacetamide might be altering the protein by means other than of active site inhibition (e.g., by facilitating a conformational change by reacting with nonactive site sulfhydryl groups), cancer procoagulant was first inhibited by PMSF to block the active site, and then the inhibited cancer procoagulant was reacted with iodoacetamide. After reductive

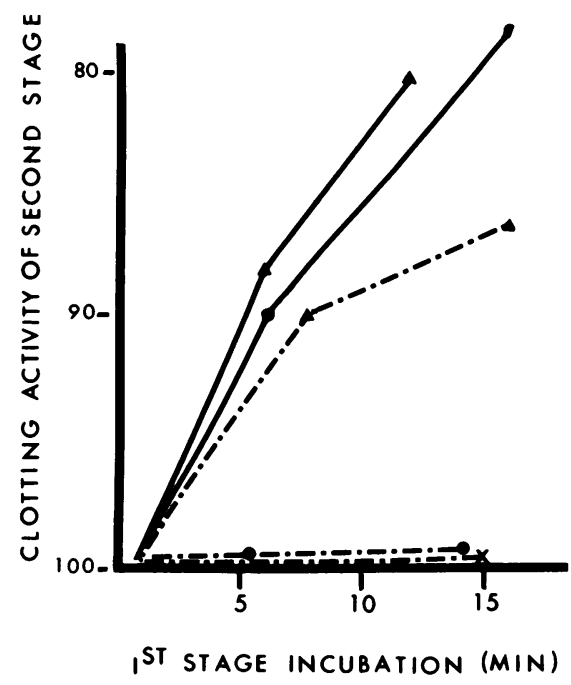

FIGURE 3 The direct activation of Factor $\mathrm{X}$ by cancer procoagulant and Russell's viper venom in a two-stage coagulation assay. The first stage of the assay contains $0.2 \mu \mathrm{g}$ of purified bovine Factor $\mathrm{X}$ in $0.5 \mathrm{ml}$ of $50 \mathrm{mM}$ Tris- $\mathrm{HCl}$ buffer (pH 7.5) containing $5 \mathrm{mM} \mathrm{CaCl}_{2}$ and $0.15 \mathrm{M} \mathrm{NaCl}, 3$ $\mu \mathrm{g}$ crude rabbit brain cephalin in $20 \mu \mathrm{l}$ saline and either $5 \mathrm{ng}$ of purified cancer procoagulant $(\boldsymbol{\Delta}-\cdot-\cdot \boldsymbol{\Delta})$ or $1 \mathrm{pg}$ of Russell's viper venom control $(\boldsymbol{\Delta} \Delta)$. To determine the amount of Factor Xa generated, timed samples $(100 \mu \mathrm{l})$ of the first stage reaction mixture were mixed with $100 \mu \mathrm{l}$ of Factor VII- and Factor X-depleted bovine plasma and $100 \mu \mathrm{l}$ of $20 \mathrm{mM} \mathrm{CaCl}$ and the clotting time of the second stage was measured with a fibrometer. To determine the effect of the inhibitor on the direct activation of Factor X, samples of the Russell's viper venom and cancer procoagulant were treated with $1 \mathrm{mM}$ iodoacetamide $(\bullet)$. Cancer procoagulant was adjusted to contain $5 \mathrm{mM}$ DFP $(x)$, the treated samples were incubated for $30 \mathrm{~min}$ at $37^{\circ} \mathrm{C}$ and assayed in the two-stage clotting assay. The clotting activity of the second stage is expressed as the normalized clotting time (seconds) of the Russell's viper venom and cancer procoagulant samples.

removal of the PMSF from the active site of cancer procoagulant, all its activity was recovered, suggesting the iodoacetamide was not causing inactivation by reacting with other sites on the proteolyic enzyme. A similar study in which DFP inhibition effectively blocked the ability of iodoacetamide to inhibit cancer procoagulant activity irreversibly suggests that DFP and iodoacetamide are reacting at the same site, or at closely adjacent sites in the enzyme.

Several investigators have examined the DFP inhibition of plant cysteine proteases, such as bromelain (29-31), ficin (18), papain $(32,33)$, and chymopapain $(34,35)$. Although there is disagreement, the studies generally conclude that commercial DFP inhibits cysteine proteases but that the inhibition of the active site sulfhydryl is due to an undefined impurity in most commercial preparations. Purified DFP phosphorylates serine $(18,35)$ or tyrosine $(31,32)$ is residual in these proteins without inhibiting their protease ac- 
tivity $(18,30-32,35)$, and the DFP impurity irreversibly inhibits the active site sulfhydryl $(18,31)$. Since the evidence presented here suggested cancer procoagulant was a cysteine protease, it seemed likely that the inhibition by DFP, a consistent and reproducible observation $(9,10,14)$, was probably due to impurities in the commercial DFP preparations that were employed. To confirm this hypothesis, DFP was catalytically hydrolyzed to diisopropylphosphate and hydrofluoric acid. The conjectured DFP impurity is not hydrolyzed under these conditions, so that during the course of the reaction inhibition of serine proteases should decrease while inhibition of cysteine proteases should remain unchanged (18). Inhibition of thrombin activity was almost complete when treated with the initial (0 min) DFP hydrolyzate mixture, but after $2 \mathrm{~h}$ the DFP hydrolyzate had lost virtually all of its ability to inhibit the clotting activity of this serine protease. In contrast, the inhibition of cancer procoagulant by the DFP hydrolyzate remained unchanged during the $2 \mathrm{~h}$ hydrolysis of DFP. Thus, all the data are consistent with the hypothesis that cancer procoagulant is a cysteine protease and its inhibition by DFP is due to an impurity in the Aldrich DFP used in this research.

DFP inhibition of cancer procoagulant activity was reversed by reductive reactivation with DTT. Although other investigators suggest that inhibition of cysteine proteases by the DFP impurity is essentially irreversible $(18,29,31)$, their data show partial $(\sim 10 \%)$ reactivation of bromelain with $5 \mathrm{mM}$ cysteine (29) and about $40 \%$ reactivation of ficin with $0.25 \mathrm{M}$ cysteine (18). Our use of DTT, a more potent reducing agent than cysteine, different reactivation conditions, and the differences in the cysteine proteases may account for our more effective reactivation of DFPinhibited cancer procoagulant.

Russell's viper venom standard was used to compare the effect of these inhibitors on a serine protease that activates Factor $X$ in a well-characterized manner $(27,36-38)$. Mercury $(0.1 \mathrm{mM})$ had little or no effect on the procoagulant activity of Russell's viper venom, which is consistent with the observations of others (38); and $1 \mathrm{mM}$ iodoacetamide seemed to stimulate the activity of Russell's viper venom. Thus, there was a clear distinction between the effect of these inhibitors on the activity of cancer procoagulant and the serine protease in Russell's viper venom. These data strongly suggest that cancer procoagulant is a cysteine protease, but unequivocal evidence from an amino acid analysis demonstrating a chemically modified active site cysteine must await the purification of milligram amounts of the enzyme.

Several groups have suggested that malignant cells produce higher levels and possibly different types of cysteine proteases than normal cells $(39,40)$. Evidence from several laboratories has suggested that malignant cells produce higher levels of "thromboplastic" coagulation factors than normal cells (41-43), but clear definition of these factors has been difficult to obtain. Although there is evidence that suggests that malignant cells produce an abnormal coagulation activity that is not associated with normal cells $(9-13){ }^{6}$ it has not been clear whether this is a known coagulation factor or whether it is something unique to the malignant state. This study suggests that a cysteine protease extracted from rabbit V2 carcinoma activates Factor $\mathrm{X}$, an observation that distinguishes it from other coagulation enzymes.

\section{ACKNOWLEDGMENTS}

Purified Factor X was kindly provided by Dr. Earl Davie, Department of Biochemistry, University of Washington, Seattle.

This investigation was supported by grant 2 R01-CA 14408 awarded by the National Cancer Institute, Department of Health, Education, and Welfare; and by General Clinical Research Center grant RR-00051, awarded by the Division of Research Resources, Department of Health, Education, and Welfare.

\section{REFERENCES}

1. Radcliffe, R. D., and P. G. Barton. 1973. Comparisons of the molecular forms of activated bovine factor X. J. Biol. Chem. 294: 6788-6795.

2. Fujikawa, K., D. H. Coan, M. E. Legaz, and W. E. Davie. 1974. The mechanism of activation of bovine factor $X$ (Stuart factor) by intrinsic and extrinsic pathways. Biochemistry. 13: 5290-5299.

3. Jesty, J., A. K. Spencer, and Y. Nemerson. 1974. The mechanism of activation of factor X. J. Biol. Chem. 45: 5614-5622.

4. Mertens, K., and R. M. Bertina. 1980. Pathways in the activation of human coagulation factor X. Biochem. J. 185: 647-658.

5. Lorand, L. 1976. Section II Blood Clotting Enzymes. Methods in Enzymology-Proteolytic Enzymes, Part B, Vol. XLV. Academic Press, Inc., New York. 31-204.

6. Bajaj, S. P., and K. G. Mann. 1973. Simultaneous purification of bovine prothrombin and factor X. J. Biol. Chem. 248: 7729-7741.

7. Purcell, G., and M. I. Barnhart. 1963. Preliminary notes. Biochim. Biophys. Acta. 78: 800-802.

8. Alexander, B., L. Pechet, and A. Kliman. 1962. Proteolysis, fibrinolysis and coagulation. Circulation. 26: 596-611.

9. Gordon, S. G., J. J. Franks, and B. Lewis. 1979. Comparison of procoagulant activities in extracts of normal and malignant human tissue. J. Natl. Cancer Inst. 63: 773-776.

10. Gordon, S. G., and B. Lewis. 1978. Comparison of procoagulant from normal and transformed fibroblasts. Cancer Res. 38: 2467-2472.

11. Hilgard, P., and P. Whur. 1980. Factor X-activating activity from Lewis lung carcinoma. Br. J. Cancer. 41: 642-643.

\footnotetext{
${ }^{6}$ Gordon, Stuart G., and B. Lewis. Manuscript submitted for publication.
} 
12. Curatolo, L., M. Colucci, A. L. Cambini, A. Poggi, L. Morasca, M. B. Donati, and N. Semararo. 1979. Evidence that cells from experimental tumours can activate coagulation factor X. Br. J. Cancer. 40: 228-233.

13. Colucci, M., L. Curatolo, M. B. Donati, and N. Semeraro. 1980. Cancer cell procoagulant activity: evaluation by an amidolytic assay. Thromb. Res. 18: 589-595.

14. Gordon, S. G., J. J. Franks, and B. Lewis. 1975. Cancer procoagulant A: a factor $\mathrm{X}$-activating procoagulant from malignant tissue. Thromb. Res. 6: 127-137.

15. Bensadoun, A., and D. Weinstein. 1976. Assay of proteins in the presence of interfering materials. Anal. Biochem. 70: 241-250.

16. Nemerson, Y., and L. P. Clyne. 1974. An assay for coagulation factor VII using factor VII-depleted bovine plasma. J. Lab. Clin. Med. 83: 301-309.

17. Wagner-Jauregg, T., B. E. Hackley, Jr., T. A. Lies, O. O. Owens, and R. Proper. 1955. Model reactions of phosphorus-containing enzyme inactivators. IV. The catalytic activity of certain metal salts and chelates in the hydrolysis of diisopropyl fluorophosphate. J. Am. Chem. Soc. 77: 922-929.

18. Gould, N. R., and I. E. Liener. 1965. Reaction of ficin with diisopropylphosphorofluoridate. Evidence for a contaminating inhibitor. Biochemistry. 4: 90-98.

19. Silverberg, S. A., Y. Nemerson, and M. Zur. 1977. Kinetics of the activation of bovine coagulation factor $\mathrm{X}$ by components of the extrinsic pathway. J. Biol. Chem. 252: 8481-8488.

20. Barrett, A. J. 1977. Proteinases in Mammalian Cells and Tissues. J. T. Dingle, editor. North-Holland Publishing Co., Amsterdam. 10-17, 181-208.

21. Perlman, G. E., and I. Lorand. 1970. Methods Enzymol. 19(Enzymes): 226-285.

22. Azanza, J. L., J. Raymond, J. M. Robin, P. Cottin, and A. Ducastaing. 1979. Purification and some physico-chemical and enzymic properties of a calcium ion-activated neutral proteinase from rabbit skeletal muscle. Biochem. J. 183: 339-347.

23. Philipp, M., I. H. Tsai, and M. L. Bender. 1979. Comparison of the kinetic specificity of subtilisin and thiolsubtilisin toward $n$-alkyl $p$-nitrophenyl esters. Biochemistry. 18: 3769-3773.

24. Ono, M., and M. Kawakami. 1977. Separation of newlysynthesized RNA by organomercurial agarose affinity chromatography. J. Biochem. (Tokyo). 81: 1247-1252.

25. McDonagh, J., W. G. Waggoner, E. G. Hamilton, B. Hindenach, and R. McDonagh. 1976. Affinity chromatography of human plasma and platelet factor XIII on organomercurial agarose. Biochim. Biophys. Acta. 446: 345-357.

26. Wilcox, R. E. 1970. Chymotrypsinogens-chymotrypsins. Methods Enzymol. 19: 64-80.

27. Fujikawa, K., M. E. Legaz, and E. W. Davie. 1972. Bovine factor $\mathrm{X}_{1}$ (Stuart factor). Mechanism of activation by a protein from Russell's viper venom. Biochemistry. 11: $4892-4899$.

28. Whitaker, J. R., and J. Perez-Villasenor. 1968. Chemical modification of papain. Arch. Biochem. Biophys. 124: 70-78.

29. Heinicke, R. M., and R. Mori. 1959. Effect of diisopropylfluorophosphate on sulfhydryl proteases. Science (Wash. D. C.). 129: 1678 .

30. Murachi, T., T. Inagami, and M. Yasui. 1965. Evidence for alkylphosphorylation of tyrosyl residues of stem bromelain by diisopropylphosphorofluoridate. Biochemistry. 4: 2815-2825.

31. Murachi, T., and M. Yasui. 1965. Alkylphosphorylation of stem bromelain by diisopropylphosphorofluoridate without inhibition of proteinase activity. Biochemistry. 4: 2275-2282.

32. Masuda, T. 1959. Studies on active groups of papain. II. Inhibition of cyanide-activated papain by diisopropylfluorophosphate. J. Biochem. (Tokyo). 46: 1569-1578.

33. Chaiken, I. W., and E. L. Smith. 1969. Reaction of a specific tyrosine residue of papain with diisopropylfluorophosphate. J. Biol. Chem. 244: 4247-4250.

34. Ebata, M., J. Tsunoda, and K. T. Yasunobu. 1966. Changes in the conformation of chymopapain during the activation process. Biochem. Biophys. Res. Commun. 22 : 455-458.

35. Ebata, M., and K. T. Yasunobu. 1963. Chymopapain. III. The inhibition of chymopapain by diisopropylphosphorofluoridate. Biochim. Biophys. Acta. 73: 132-144.

36. DiScipio, R. G., M. A. Hermodson, and E. W. Davie. 1977. Activation of human factor $\mathrm{X}$ (Stuart factor) by a protease from Russell's viper venom. Biochemistry. 16: 5253-5259.

37. Kisiel, W., M. A. Hermodson, and E. W. Davie. 1976. Factor X activating enzyme from Russell's viper venom: isolation and characterization. Biochemistry. 15: 49014906.

38. Furukawa, Y., Y. Matsunaga, and K. Hayashi. 1976. Purification and characterization of a coagulant protein from the venom of Russell's viper. Biochim. Biophys. Acta. 453: 48-61.

39. Recklies, A. D., K. J. Tiltman, T. A. M. Stoker, and A. R Poole. 1980. Secretion of proteinases from malignant and nonmalignant human breast tissue. Cancer Res. 40: 550-556.

40. Harington, J. S. 1967. The sulfhydryl group and carcinogenesis. Adv. Cancer Res. 10: 247-307.

41. Holyoke, E. D., A. L. Frank, and L. Weiss. 1972. Tumor thromboplastin activity in vitro. Int. J. Cancer. 9: 258-263.

42. Khato, J., M. Suzuki, and H. Sato. 1974. Quantitative study on thromboplastin in various strains of Yoshida ascites hepatoma cells in rat. Gann. 65: 289-294.

43. Boggust, W. A., D. J. O'Brien, R. A. Q. O'Meara, and R. D. Thornes. 1963. The coagulative factors of normal human and human cancer tissue. Ir. J. Med. Sci. 477: 131-144. 